\title{
Enhanced Electrochemical Performance Promoted by Tin in Silica Anode Materials for Stable and High-Capacity Lithium-Ion Batteries
}

\author{
Xuli Ding *(D), Daowei Liang and Hongda Zhao
}

check for updates

Citation: Ding, X.; Liang, D.; Zhao,

H. Enhanced Electrochemical Performance Promoted by Tin in Silica Anode Materials for Stable and High-Capacity Lithium-Ion Batteries. Materials 2021, 14, 1071. https:// doi.org/10.3390/ma14051071

Academic Editor: Suzy Surblé

Received: 18 January 2021

Accepted: 9 February 2021

Published: 25 February 2021

Publisher's Note: MDPI stays neutral with regard to jurisdictional claims in published maps and institutional affiliations.

Copyright: (c) 2021 by the authors. Licensee MDPI, Basel, Switzerland. This article is an open access article distributed under the terms and conditions of the Creative Commons Attribution (CC BY) license (https:/ / creativecommons.org/licenses/by/ $4.0 /)$.
School of Science, Jiangsu University of Science and Technology, 666 Changhui Road, Zhenjiang 212100, China; Leong1664988857@163.com (D.L.); zhd1787278660@163.com (H.Z.)

* Correspondence: xuliding@just.edu.cn

\begin{abstract}
Although the silicon oxide $\left(\mathrm{SiO}_{2}\right)$ as an anode material shows potential and promise for lithium-ion batteries (LIBs), owing to its high capacity, low cost, abundance, and safety, severe capacity decay and sluggish charge transfer during the discharge-charge process has caused a serious challenge for available applications. Herein, a novel 3D porous silicon oxide@Pourous Carbon@Tin ( $\mathrm{SiO}_{2} @ \mathrm{Pc} @ \mathrm{Sn}$ ) composite anode material was firstly designed and synthesized by freeze-drying and thermal-melting self-assembly, in which $\mathrm{SiO}_{2}$ microparticles were encapsulated in the porous carbon as well as $\mathrm{Sn}$ nanoballs being uniformly dispersed in the $\mathrm{SiO}_{2} @$ Pc-like sesame seeds, effectively constructing a robust and conductive 3D porous Jujube cake-like architecture that is beneficial for fast ion transfer and high structural stability. Such a $\mathrm{SiO}_{2} @ \mathrm{Pc} @ S n$ micro-nano hierarchical structure as a LIBs anode exhibits a large reversible specific capacity $\sim 520 \mathrm{mAh} \cdot \mathrm{g}^{-1}$, initial coulombic efficiency (ICE) 52\%, outstanding rate capability, and excellent cycling stability over 100 cycles. Furthermore, the phase evolution and underlying electrochemical mechanism during the charge-discharge process were further uncovered by cyclic voltammetry $(\mathrm{CV})$ investigation.
\end{abstract}

Keywords: porous carbon; silica; tin; anode materials; lithium-ion batteries

\section{Introduction}

Lithium-ion batteries (LIBs) have been regarded as one of the critical energy storage technologies that can be widely used in portable electronics and grid-scale energy storage due to their high energy density and cycle longevity to make a fossil fuel-free environment possible [1-5]. With the advent of electric vehicles (EV) in recent years, the traditional commercialized LIBs are obviously insufficient to meet the requirement owning to their limited capacities. Therefore, it is highly desired for LIBs with higher energy and power densities as well as lower cost to be developed [6-8].

According to the working principle of LIBs, the electrode materials play a critical role in the further improvement of the battery performance [9-16]. High-capacity and low-cost materials have triggered vast interest in the past few years [15-21], which can bring great promise for next-generation LIBs with a higher price-performance ratio. Silica $\left(\mathrm{SiO}_{2}\right)$ has recently captured great attention as a promising candidate anode materials for LIBs because of its suitable working potential $\left(\sim 0.25 \mathrm{~V}\right.$ vs. $\left.\mathrm{Li} / \mathrm{Li}^{+}\right)$, proper theoretical specific capacity $\left(\sim 1960 \mathrm{mAh} \cdot \mathrm{g}^{-1}\right)$, lesser volume variation $(\sim 100 \%)$, and expanded cycling lifespan compared to silicon and other alloys [22-39]. In addition, $\mathrm{SiO}_{2}$ is one of the most abundant materials on earth, and its environmentally friendly and low-cost nature further turns it into an alternative electrode material [25-30]. However, the development of $\mathrm{SiO}_{2}$-based anode materials so far has been impeded due to its poor electrical conductivity and sluggish charge transfer kinetics. To overcome these limitations, extensive research efforts have been dedicated to the development of $\mathrm{SiO}_{2}$-based composite materials and structures, such as carbon-coated $\mathrm{SiO}_{2}$ particles $[32,35,36], \mathrm{SiO}_{2} / \mathrm{Cu}$ polyacrylonitrile$\mathrm{C}$ composite [33], $\mathrm{Sn}\left(\mathrm{SnO}_{2}\right)-\mathrm{SiO}_{2}$ /graphene nanocomposites [37], $\mathrm{Bi}_{2} \mathrm{~S}_{3} @ \mathrm{SiO}_{2}$ core-shell 
microwires [38], $\mathrm{Ni} / \mathrm{SiO}_{2}$ hierarchical hollow spheres [39], and so on [34,40]. Even though significant progress has been achieved, the commercialization of $\mathrm{SiO}_{2}$-based anodes is still restricted by the low electrochemical activity. On the other hand, metallic tin ( $\mathrm{Sn}$ ) has a good electrical conductivity $\left(8.7 \times 10^{6} \mathrm{~S} \cdot \mathrm{m}^{-1}\right)$ and low melting point $\left(\sim 232{ }^{\circ} \mathrm{C}\right)$. When used as an electrode material, it shows a high theoretical capacity of $994 \mathrm{mAh} \cdot \mathrm{g}^{-1}$ with the formation of $\mathrm{Li}_{4.4} \mathrm{Sn}$ and fitting working potential $(\sim 0.5 \mathrm{~V})$. However, the huge volume changes $(\sim 260 \%)$ it suffers during Li alloying/dealloying can always lead to rapid fading of capacity and subsequently poor cyclability [41-47].

Taking advantages of both $\mathrm{SiO}_{2}$ and $\mathrm{Sn}$, herein, a feasible tactics was developed to construct porous silicon oxide@Pourous Carbon@Tin $\left(\mathrm{SiO}_{2} @ \mathrm{Pc} @ S n\right)$ composites with tunable $\mathrm{SiO}_{2}$ to $\mathrm{Sn}$ molar ratios to synergistically storage $\mathrm{Li}$ in both porous $\mathrm{SiO}_{2}$ and Sn. The $\mathrm{SiO}_{2} @ \mathrm{Pc} @ S n$ composite was fabricated using a simple and scalable freezingdrying and low-temperature thermal-melting combined method. The obtained composites possessed several advantageous features: Firstly, the porous structure in the composites largely shortened the transport path for Li ions and provided the buffering space for volume change during the charging/discharging process; secondly, porous $\mathrm{C}(\mathrm{Pc})$ and $\mathrm{SiO}_{2}$ provided a rigid skeleton with long cycle stability; thirdly, the presence of $\mathrm{Sn}$ and $\mathrm{Pc}$ could improve the electrical conductivity of the $\mathrm{SiO}_{2}$-based electrode. The synergetic effect of porous $\mathrm{SiO}_{2}, \mathrm{Pc}$, and $\mathrm{Sn}$ nano-ball empowered the fabricated $\mathrm{SiO}_{2} @ \mathrm{Pc} @ S n$ composite electrodes to be competent to show good electrochemical performance, including a stable and long cycling life, low electrochemical impedance, and enhanced specific capacity, which demonstrated a fascinating potential as a promising anode for the next-generation LIBs.

\section{Experimental Section}

\subsection{Preparation of $\mathrm{SiO}_{2} @ P c$ Composites Material}

Diatomite (325 mesh, Sinopharm Chemical Reagent Co., Ltd. Shanghai, China) was ground for $10 \mathrm{~h}$ by a high-energy ball mill, then the sample was dispersed in the glucose aqueous solution by ultrasonic for $15 \mathrm{mi}$. After that, the freeze-drying process for $60 \mathrm{~h}$ was carried out, in which the mass ratio of $\mathrm{SiO}_{2}$ to glucose was 1:1 $(w / w)$. Then, the freeze-drying samples were transferred to a tube furnace and carbonized for $3 \mathrm{~h}$ at $500{ }^{\circ} \mathrm{C}$ in an $\mathrm{Ar} / \mathrm{H}_{2}$ gas environment to obtain $\mathrm{SiO}_{2} @ \mathrm{Pc}$ composites.

\subsection{Preparation of $\mathrm{SiO}_{2} @ P c @ S n$ Composites Material}

The previously obtained $\mathrm{SiO}_{2} @ \mathrm{Pc}$ from the above step was weighed at ratio of 1:1 $(w / w)$ with Sn powders (325 mesh, Sinopharm Chemical ReagentCo., Ltd. Shanghai, China) and mixed fully. Then the mixture was transferred to a tubular furnace (OTF1200X), and heated at a rate of $5{ }^{\circ} \mathrm{C} / \mathrm{min}$ to $300^{\circ} \mathrm{C}$, keeping for $1 \mathrm{~h}$ in an $\mathrm{Ar} / \mathrm{H}_{2}$ protect gas. After that, the sample of $\mathrm{SiO}_{2} @ \mathrm{Pc} @ \mathrm{Sn}$ was obtained via rapid cooling.

\subsection{Battery Assembly and Electrochemical Measurements}

The Celgard 2320 (Shenzhen, China) film was used as a membrane and lithium foil as a pair electrode to conduct electrochemical experiments on the CR2032 (Shenzhen, China) coin battery. The experimental electrolyte was configured of $1.0 \mathrm{M} \mathrm{LiPF}_{6}$ dissolved in ethylene carbonate (EC) and diethyl carbonate (DEC) by volume 1:1. The working electrode was composed of $70 \mathrm{wt} . \%$ active materials, $15 \mathrm{wt} . \%$ polyvinylidene fluoride (PVDF) binder, and $15 \mathrm{wt} . \%$ Super P. After fully mixing and grinding, the slurry was spread on the copper foil evenly, and then dried in an oven at $50^{\circ} \mathrm{C}$ for $12 \mathrm{~h}$. The battery was assembled in a glove box filled with Ar gas and the oxygen and water content below 1.0 PPM. After assemblage, the batteries were set aside for $8 \mathrm{~h}$ at room temperature. The electrochemical performance was tested by electrochemical impedance spectroscopy (EIS) and cyclic voltammetry (CV) on a DH7001 electrochemical workstation, and the scanning rate of CV was set in the range of $0.1-0.5 \mathrm{mV} \mathrm{s}^{-1}$ with an applied potential 2-0 V, and the frequency range for EIS measurement was set in $1.0 \mathrm{MHz}-0.1 \mathrm{~Hz}$. All batteries' simulation cycling and charge/discharge were conducted on a land battery cabinet (LAND 
CT2001A, Wuhan, China). In the batteries' evaluation process, the cut-off voltage was $0.005 \mathrm{~V} \mathrm{vs} \mathrm{Li} / \mathrm{Li}^{+}$for discharge and $1.5 \mathrm{~V}$ for charge. All specific capacity was calculated based on the proportion of the active material in the whole electrode.

\subsection{Characterization}

The morphology and structure of $\mathrm{SiO}_{2} @ \mathrm{Pc} @ S n$ were obtained by a field-emission scanning electron microscope (FESEM, JEOL JMS-7001-F, JEOL, Tokyo, Japan). The element mapping was measured by the EDS instrument equipped in the FESEM. The phase composition of the material was obtained by X'Pert PRO diffractometer (XRD, Shimadzu, Japan: $\mathrm{XRD}-6000, \mathrm{Cu}-\mathrm{K}$ radiation, $0.15406 \mathrm{~nm}, \lambda=1.5406 \AA$ ), the measurement angle was between $10-80^{\circ}$, and the scanning rate was $10^{\circ} / \mathrm{min}$. Raman spectroscopy was used to characterize the form of carbon, and the excited wavelength of the laser was $532 \mathrm{~nm}$ (Raman, InVia and Ntegra Spectra, Renishaw \& NT-MDT, London, UK). The thermogravimetry (TG) analysis was performed by the vertical zero friction dilatometer L75VS Linseis (Selb, Germany) from 25 to $800{ }^{\circ} \mathrm{C}$ in air to calculate the carbon weight percent in the composite.

\section{Results and Discussion}

The preparation flow chart of the $\mathrm{SiO}_{2} @ \mathrm{Pc} @ S n$ composite is shown in Figure 1. As depicted in the schematic diagram, firstly, the $\mathrm{SiO}_{2} @ \mathrm{Pc}$ composite with a porous structure was prepared by the freeze-drying method, and secondly, the $\mathrm{SiO}_{2} @ \mathrm{Pc} @ S n$ composite was obtained via the low-temperature thermal melting and self-assembly process.

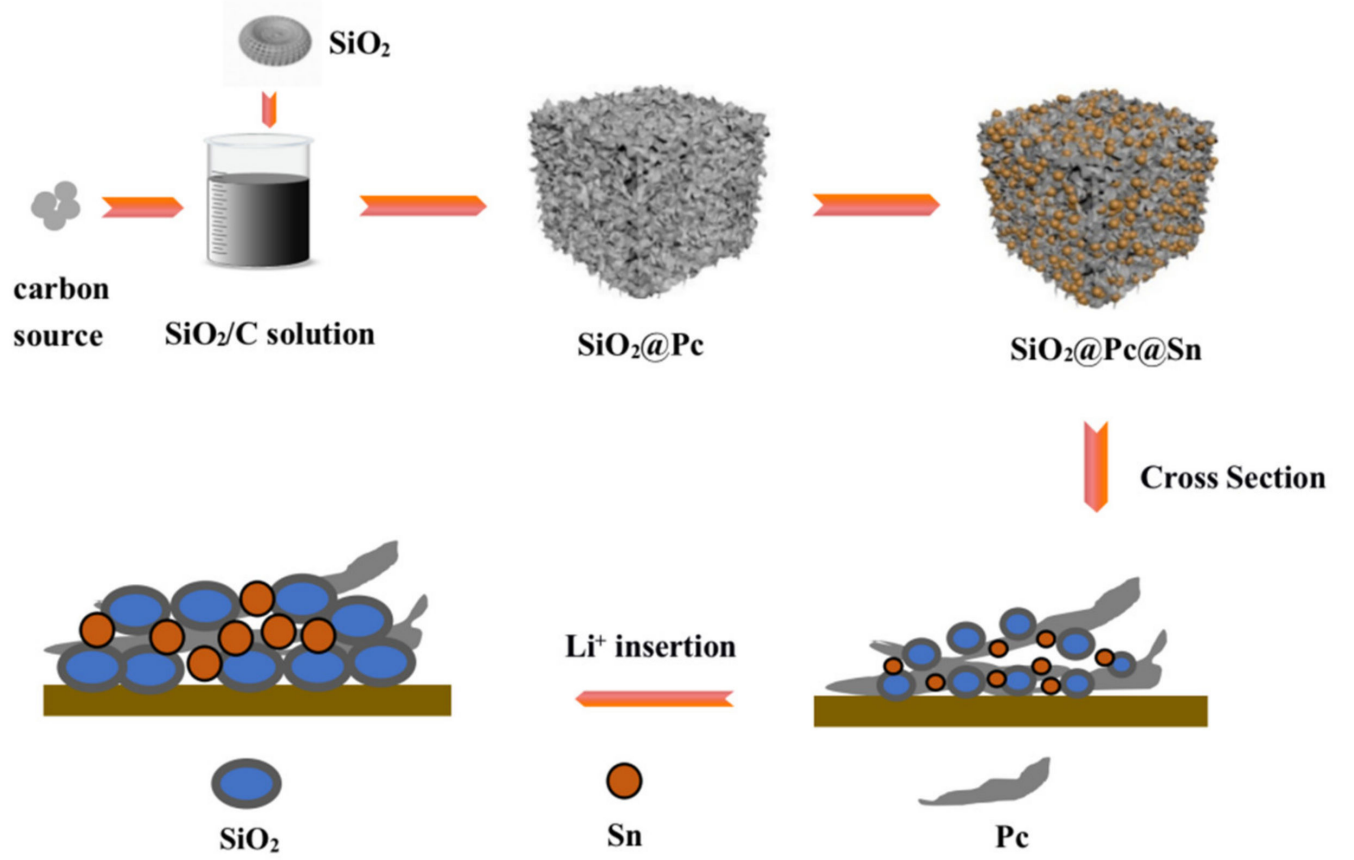

Figure 1. Schematic diagram of the synthesize process of silicon oxide@Pourous Carbon@Tin $\left(\mathrm{SiO}_{2} @ \mathrm{Pc} @ \mathrm{Sn}\right)$ composite.

Figure 2a shows the comparison of the XRD pattern of $\mathrm{SiO}_{2}, \mathrm{SiO}_{2} @ \mathrm{Pc}, \mathrm{SiO}_{2} @ \mathrm{Pc} @ S n$, and PDF card of standard XRD, correspondingly. The characteristic peaks at $21.6^{\circ}$ and $35.6^{\circ}$ belonged to $\mathrm{SiO}_{2}$ [26], and the peak value of $\mathrm{SiO}_{2} @ \mathrm{Pc}$ was consistent with that of $\mathrm{SiO}_{2}$, indicating that $\mathrm{SiO}_{2}$ did not change significantly after Pc coating. In the $\mathrm{SiO}_{2} @ \mathrm{Pc} @ S n$ composite, the characteristic peaks for $\mathrm{Sn}$ were centered at $30.6^{\circ}, 32.1^{\circ}, 43.9^{\circ}, 44.9^{\circ}$, and $55.3^{\circ}$. The characteristic peaks that belonged to $\mathrm{SiO}_{2}$ and $\mathrm{Sn}$ in the $\mathrm{SiO}_{2} @ \mathrm{Pc} @ S n$ composite were matched well with the standard PDF cards. The synthesized Pc was characterized by the Raman spectrum as indicated in Figure 2. It can be seen that the peaks around 1357 and $1591 \mathrm{~cm}^{-1}$ corresponded to the disordered D peak and graphitized $\mathrm{G}$ peak for the obtained 
Pc. The D peak was generally the crystallization defect of carbon atoms and the G peak represented the in-plane vibration of $\mathrm{sp}^{2}$ hybridization of carbon atoms [48,49]. The existence of the $G$ peak and D peak indicates that the microstructure of Pc in the $\mathrm{SiO}_{2} @ \mathrm{Pc} @ S n$ composite was graphitized carbon. In addition, the main peak of $\mathrm{SiO}_{2}$ at $480-490 \mathrm{~cm}^{-1}$ was not present in the current Raman spectrum $500-3000 \mathrm{~cm}^{-1}$ [27], while the peak around $1080 \mathrm{~cm}^{-1}$ under $\mathrm{D}$ peak of carbon was also invisible due to the encapsulation of $\mathrm{SiO}_{2}$ in a carbon shell [26]. From the TG analysis result in the Raman spectrum, the $\mathrm{C}$ weight percent in the $\mathrm{SiO}_{2} @ \mathrm{Pc}$ composite was $\sim 27.3 \%$.

(a)

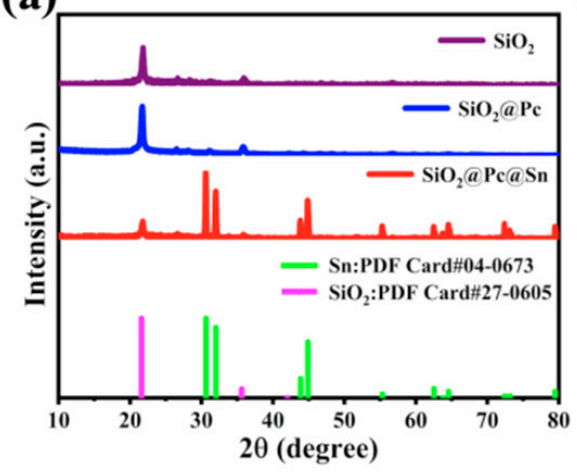

(b)

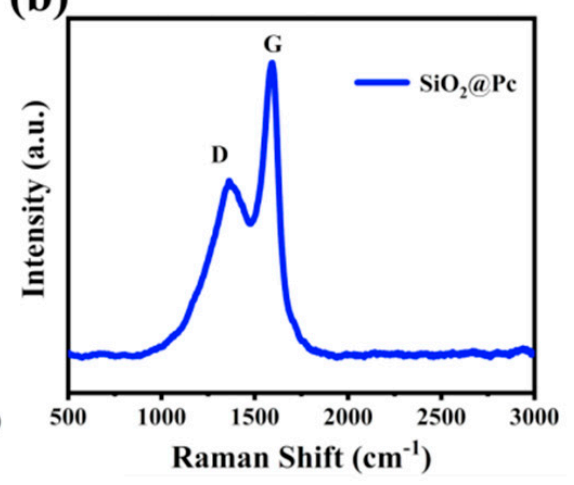

(c)

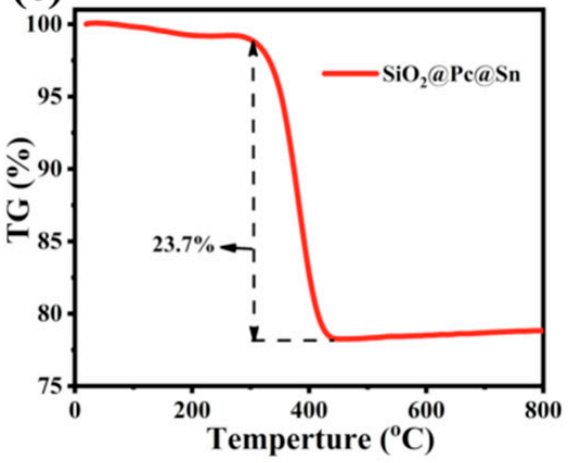

Figure 2. (a) XRD patterns of different samples; (b) Raman spectrum of $\mathrm{SiO}_{2} @ \mathrm{Pc}$; (c) thermogravimetry (TG) diagram for the $\mathrm{SiO}_{2} @ \mathrm{Pc}$.

The morphology and elements distribution of the obtained $\mathrm{SiO}_{2} @ \mathrm{Pc} @ S n$ composite was measured by scanning electron microscopy (SEM). As shown in Figure 3, the pristine $\mathrm{SiO}_{2}$ was in the shape of a sunflower (Figure 3a), and its average size was between 20-40 $\mu \mathrm{m}$, with many nano-pores on the surface (Figure 3b). The size of the pores was in the range of 50-600 nm (Figure 3b). From the images as shown in Figure 3c, after rapid cooling, the Sn nano-balls were formed and dispersed uniformly in the $\mathrm{SiO}_{2} @ \mathrm{Pc}$ composite, which filled into the pores in Pc or embedded among the $\mathrm{SiO}_{2} @ \mathrm{Pc}$ blocks. As shown in Figure $3 \mathrm{f}$, the statistical distribution of size for the $\mathrm{Sn}$ balls was mainly centered around $100 \mathrm{~nm}$. The element mapping for $\mathrm{Si}, \mathrm{Sn}$, and $\mathrm{C}$ in the $\mathrm{SiO}_{2} @ \mathrm{Pc} @ S n$ composite is shown in Figure $3 \mathrm{~g}-\mathrm{i}$. From the result, it is found that three elements are distributed in all the areas detected in the $\mathrm{SiO}_{2} @ \mathrm{Pc} @ S n$.

The electrochemical performance is displayed in Figure 4. The charge/discharge curves of different samples at the same current density of $100 \mathrm{~mA} \cdot \mathrm{g}^{-1}$ are compared in Figure 4a. It was found that the first discharge capacity reached to 1228 for $\mathrm{SiO}_{2} @ P c @ S n$, 990 for $\mathrm{SiO}_{2} @ \mathrm{Pc}, 672$ for bare $\mathrm{SiO}_{2}$, and $352 \mathrm{~mA} \cdot \mathrm{h} \cdot \mathrm{g}^{-1}$ for the synthesized Pc. The initial coulomb efficiency (ICE) was $52 \%, 37.7 \%, 29.9 \%$, and $27.4 \%$, respectively. The improved specific capacity and ICE of $\mathrm{SiO}_{2} @ \mathrm{Pc} @ S n$ were attributed to the fact that Pc and Sn can improve the electrical conductivity of the composite and enhance the electrochemical activity of $\mathrm{SiO}_{2}$. The poor conductivity of $\mathrm{SiO}_{2}$ was the cause of the low initial coulombic efficiency, and most of $\mathrm{Li}$ ions combined with $\mathrm{SiO}_{2}$ to produce irreversible $\mathrm{Li}_{4} \mathrm{SiO}_{4}$ and $\mathrm{Li}_{2} \mathrm{O}$ at the first charge and discharge [50,51], while the presence of Pc and Sn improved the whole electrical conductivity of $\mathrm{SiO}_{2} @ \mathrm{Pc} @ S n$, which is helpful for the electrons to arrive at the surface of $\mathrm{SiO}_{2}$, and as a result, facilitated the $\mathrm{Li}$ ions transfer in the composite. Meanwhile, the existence of Pc further prevented the by-products brought by the direct reaction between electrolyte and $\mathrm{SiO}_{2}$ and $\mathrm{Sn}$, thus improving the ICE of the composite [52]. The cycling performance at $100 \mathrm{~mA} \cdot \mathrm{g}^{-1}$ is compared in Figure $4 \mathrm{~b}$. It is evident that $\mathrm{SiO}_{2} @ \mathrm{Pc} @ S n$ shows the highest specific capacity and best capacity retention through 100 cycles. While for bare $\mathrm{SiO}_{2}$, the capacity underwent continuous increasing during the initial 100 cycles that changed from the initial 200 to $400 \mathrm{~mA} \cdot \mathrm{h} \cdot \mathrm{g}^{-1}$ after 100 cycles. Though the capacity of $\mathrm{SiO}_{2} @ \mathrm{Pc}$ could not reach $\mathrm{SiO}_{2} @ \mathrm{Pc} @ S n$, it was still better than bare $\mathrm{SiO}_{2}$ and 
Pc. Moreover, the rate capability for different samples was listed in Figure 4c. It is clear that the $\mathrm{SiO}_{2} @ \mathrm{Pc} @ S n$ exhibited capacities of $650,610,580$, and $520 \mathrm{~mA} \cdot \mathrm{h} \cdot \mathrm{g}^{-1}$ at 100,200 , 500 , and $1000 \mathrm{~mA} \cdot \mathrm{g}^{-1}$, respectively, whereas the bare $\mathrm{SiO}_{2}$ and $\mathrm{SiO}_{2} @ \mathrm{Pc}$ exhibited a lower capacity and faster capacity decay. Obviously, the rate capability of $\mathrm{SiO}_{2} @ \mathrm{Pc} @ \mathrm{Sn}$ was better than that of the others, especially at high current density due to the fact that Pc and Sn had better conductivity than $\mathrm{SiO}_{2}$, which provided higher mobility for $\mathrm{Li}$ ion diffusion through the whole electrode. Without the addition of other assistance, such as an electrolyte additive (for instance, FEC) and so on, the good rate capability and stable cycling performance of $\mathrm{SiO}_{2} @ \mathrm{Pc} @ S n$ was believed to be originated from the unique structure. Firstly, the built-in void in $\mathrm{Pc}$ and $\mathrm{SiO}_{2}$ shorted the $\mathrm{Li}$ ions transfer distance in the electrode; secondly, $\mathrm{Sn}$ and Pc were conductive for electrons and ions, and the face-to-face contact between Pc and $\mathrm{SiO}_{2}$ as well as $\mathrm{Sn}$ aroused more efficient channels for fast transfer of electrons and $\mathrm{Li}$ ions $[15,17]$. The $\mathrm{CV}$ test could detect electrode surface reaction process, electrochemical activity, and reversibility of the active material. Figure $4 \mathrm{~d}$ is the CV curve of $\mathrm{SiO}_{2} @ \mathrm{Pc} @ S n$. As shown, the cathode peak of $0.98 \mathrm{~V}$ in the first cathode scan was caused by electrolyte decomposition and the generation of the SEI layer [50], while the reductive peaks at 0.63 and $0.32 \mathrm{~V}$ were attributed to the phase $\mathrm{Li}_{x} \mathrm{SiO}_{y}$ and $\mathrm{Li}_{x} \mathrm{Si}$ formed while $\mathrm{SiO}_{2}$ was combined with $\mathrm{Li}^{+}$in the discharge process [30,40]. On the contrary, the oxidation peaks at $0.64,0.74$, and $0.82 \mathrm{~V}$ were caused by the dealloying process of $\mathrm{Li}_{x} \mathrm{Sn}$ and $\mathrm{Li}_{2} \mathrm{Si}_{2} \mathrm{O}_{5}$ [53].

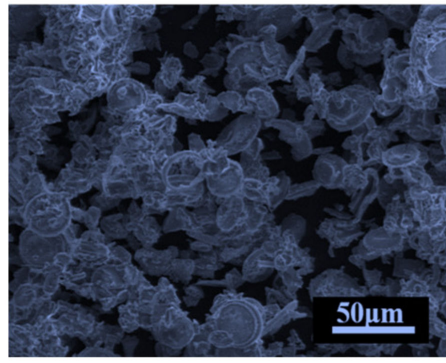

(a)

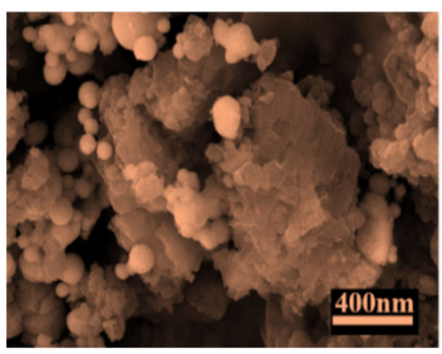

(d)

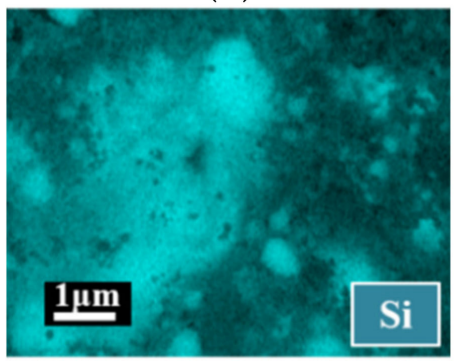

(g)

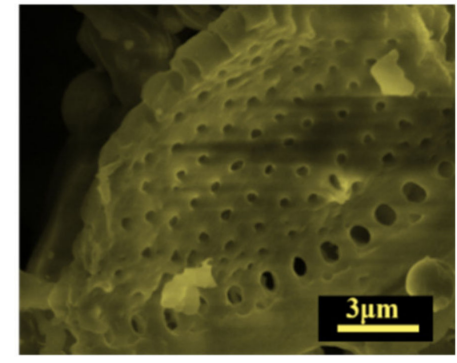

(b)

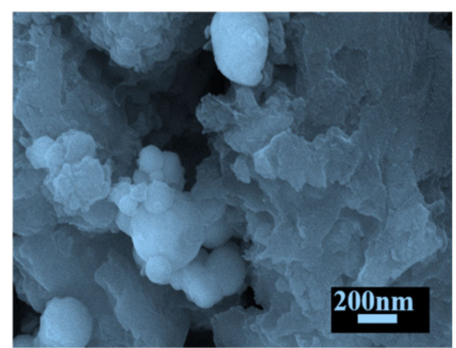

(e)

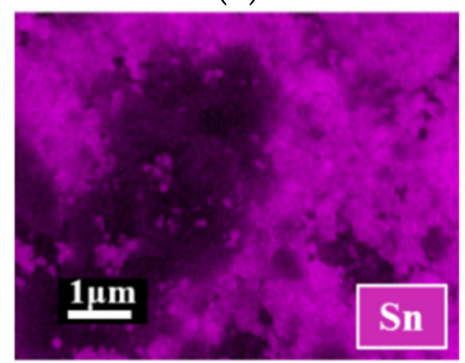

(h)

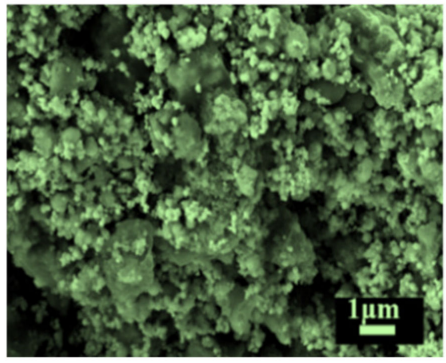

(c)

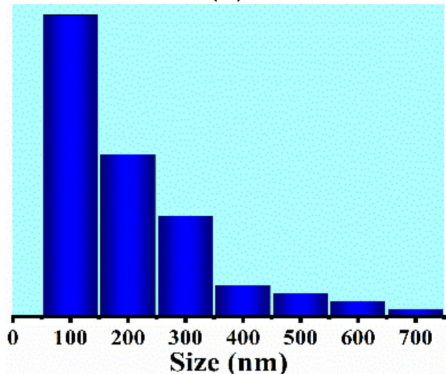

(f)

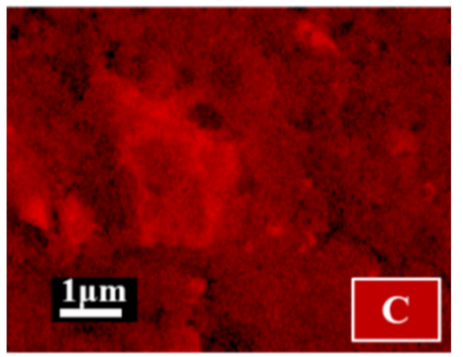

(i)

Figure 3. (a,b) SEM of bare $\mathrm{SiO}_{2}$ with different magnification; (c-e) SEM of $\mathrm{SiO}_{2} @ \mathrm{Pc} @ S n$ with different magnification; (f) size distribution for $\mathrm{Sn}$ in the $\mathrm{SiO}_{2} @ \mathrm{Pc} @ S n$ composite; (g,i) element mapping of $\mathrm{SiO}_{2} @ \mathrm{Pc} @ S n$ for $\mathrm{Si}$ (g); $\mathrm{Sn}(\mathbf{h})$; and C (i). 
(a)

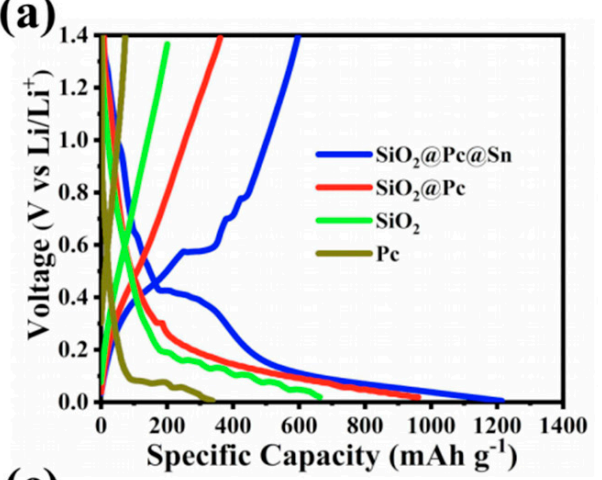

(c)

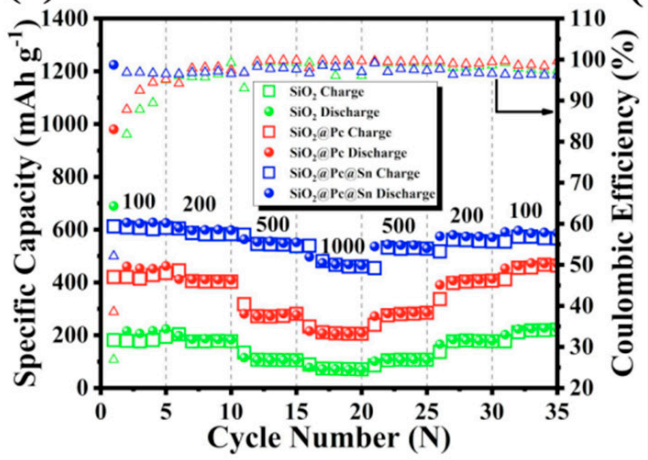

(b)

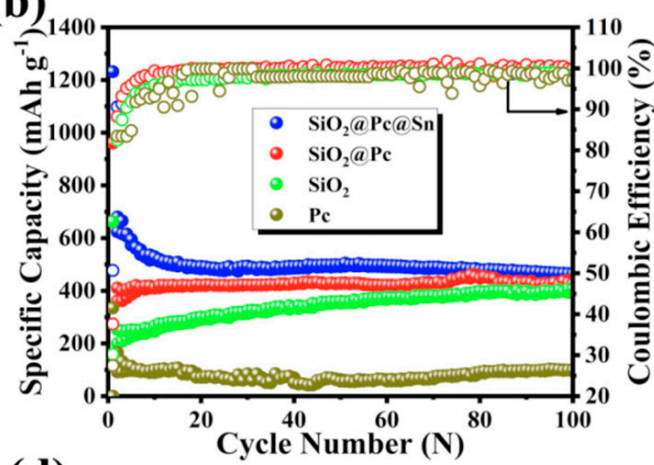

(d)

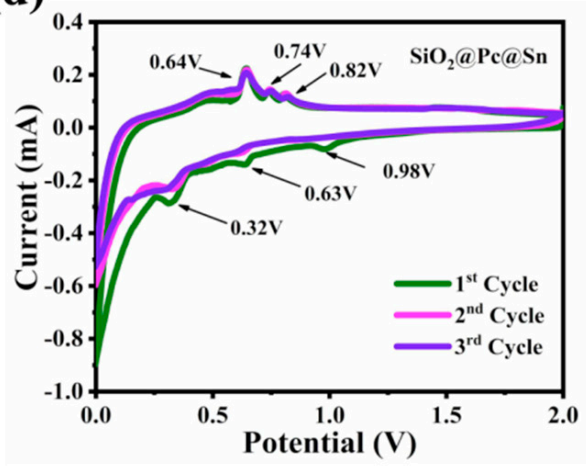

Figure 4. (a) Charge/discharge curve of different samples; (b) cycling performance curve of different samples; (c) the rate performance for different samples; (d) cyclic voltammetry (CV) curve of $\mathrm{SiO}_{2} @ \mathrm{Pc} @ S n$.

Furthermore, the electrochemical impedance spectra (EIS) were compared and analyzed in Figure 5. From the Nyquist plots diagram of different samples, as shown in Figure $5 \mathrm{a}$, it was found that all impedance spectra consisted of a semicircle in the high frequency region and an inclined line in the low frequency region, which corresponded to the $\mathrm{Li}^{+}$migration resistance and interface contact resistance in the active materials, respectively [54,55]. The impedance resistance was 205 for bare $\mathrm{SiO}_{2}, 129$ for the $\mathrm{SiO}_{2} @ \mathrm{Pc}$, and $77 \Omega$ for $\mathrm{SiO}_{2} @ \mathrm{Pc} @ S n$, indicating that the migration impedance of Li ions was minimal in the active material of $\mathrm{SiO}_{2} @ \mathrm{Pc} @ S$. In addition, EIS was often used in the qualitative determination of Li ions' diffusion coefficient in LIB materials. Figure $5 b$ is the plots of correlation curve of $Z_{r e}$ (real part of impedance) and $w^{-1 / 2}$ ( $w$ is the frequency) within the frequency range of $1-0.1 \mathrm{~Hz}$ for the electrode composed of different materials. According to the relation, $Z_{\mathrm{re}}=\mathrm{G}-k \cdot w^{-1 / 2}$, where, $k$ is the slope of the correlation curve between $Z_{\text {re }}$ and $w^{-1 / 2}$, from which the diffusion coefficient of lithium ions in different electrode materials can be qualitatively deduced [20]. In order to ensure the accuracy of the experiment, each set of data tested 5-10 batteries for analysis. From the fitting results (Figure $5 b$ ), the curve slopes $k$ of $\mathrm{SiO}_{2}, \mathrm{SiO}_{2} @ \mathrm{Pc}$, and $\mathrm{SiO}_{2} @ \mathrm{Pc} @ \mathrm{Sn}$ were $0.33,0.20$ and 0.07 , respectively. The result showed that the diffusion coefficient of $\mathrm{Li}^{+}$was the largest in the $\mathrm{SiO}_{2} @ \mathrm{Pc} @ \mathrm{Sn}$ composite according to the relation formula [21], $\mathrm{D}_{\mathrm{Li}+}=\mathrm{A} / k$, where, $\mathrm{A}$ is constant related to the Li ions content and electrode area, etc.

Meanwhile, the $\mathrm{CV}$ measurement with different scanning rates $\left(\mathrm{mV} \cdot \mathrm{s}^{-1}\right)$ is shown in Figure 6. The CV curves of $\mathrm{SiO}_{2}$ (Figure 6a), $\mathrm{SiO}_{2} @ \mathrm{Pc}$ (Figure 6b), and $\mathrm{SiO}_{2} @ \mathrm{Pc} @ \mathrm{Sn}$ (Figure 6c) electrodes under scanning rates of $0.1,0.2,0.3,0.4$, and $0.5 \mathrm{mV} \cdot \mathrm{s}^{-1}$ were measured. The obtained peak current $I_{\max }$ and the quadratic root of scanning rate $v^{1 / 2}$ were fitted linearly, from which the diffusion strength of $\mathrm{Li}^{+}$in different electrode materials could be qualitatively determined. According to the Randle-Sevcik equation: $I_{\max }=\mathrm{A} v \cdot{ }^{1 / 2} \cdot \mathrm{D}_{\mathrm{oLi}}[56]$, where A is the constant related to charge and surface area, $v$ is the scanning rate of $\mathrm{CV}$, and $\mathrm{D}_{\mathrm{oLi}}$ is the diffusion coefficient of $\mathrm{Li}^{+}$in oxide [54]. According to 
the test results shown in Figure 6d, the slopes were 0.49, 0.44, and 0.12 for $\mathrm{SiO}_{2} @ \mathrm{Pc} @ \mathrm{Sn}$, $\mathrm{SiO}_{2} @ \mathrm{Pc}$, and bare $\mathrm{SiO}_{2}$, respectively, indicating that the diffusion coefficient of $\mathrm{Li}^{+}$ions was the highest in $\mathrm{SiO}_{2} @ \mathrm{Pc} @ S$ n compared with the two others [57]. The result was also consistent with the fitting results of the correlation curve between $Z_{r e}$ and $v^{-1 / 2}$ of EIS in the frequency range of $1-0.1 \mathrm{~Hz}$ (Figure 5b), which further demonstrated that Sn could improve the electrochemical performance of $\mathrm{SiO}_{2}$-based anode materials for LIBs.

(a)

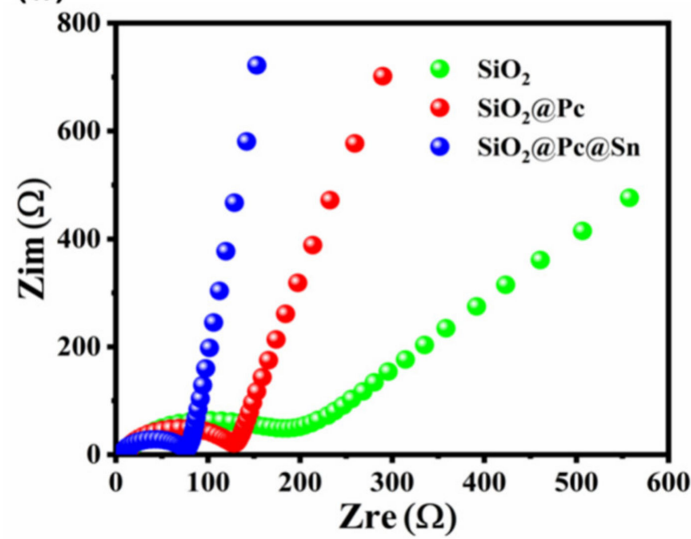

(b)

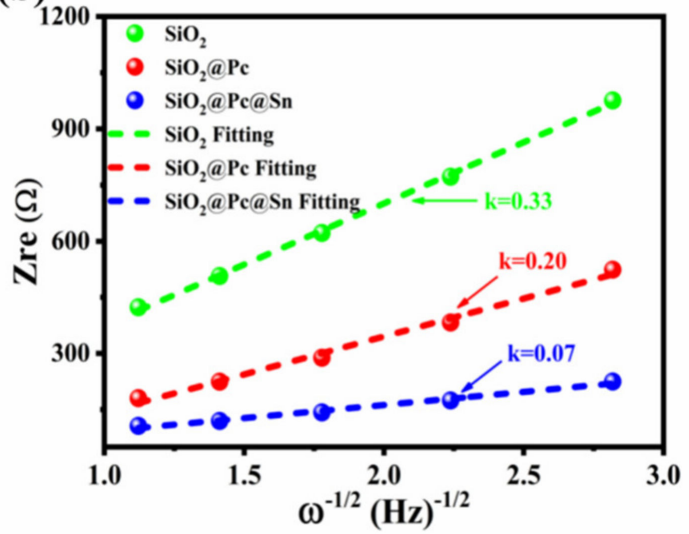

Figure 5. (a) Comparison for the Nyquist diagram of different samples; (b) impedance real part $Z_{r e}$ Vs $w^{-1 / 2}$ in the frequency range $1-0.1 \mathrm{~Hz}$.

(a)
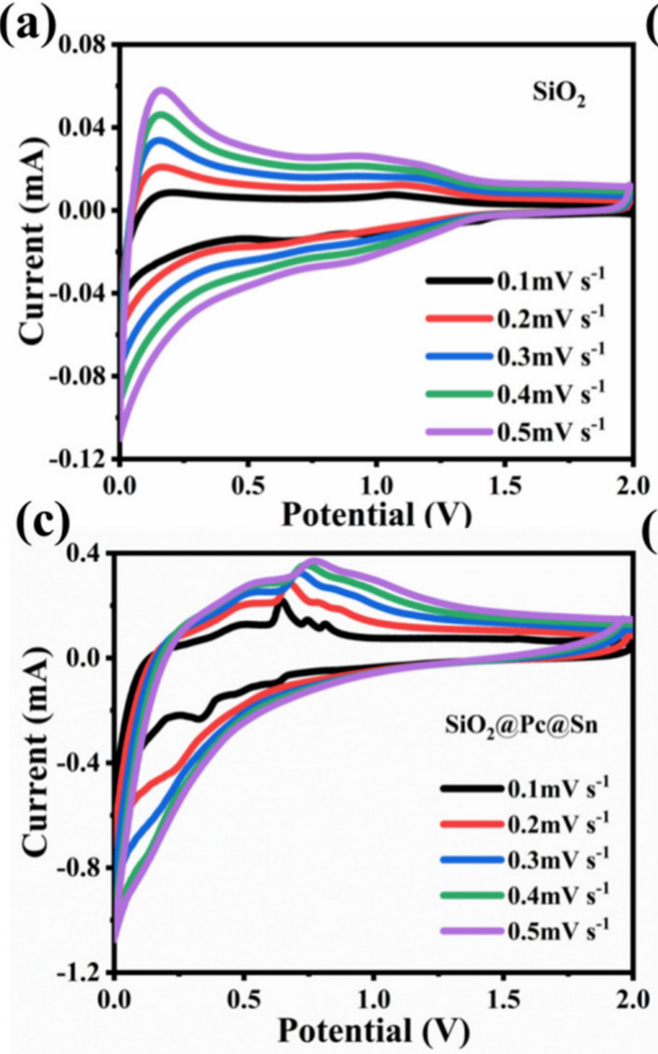

(b)

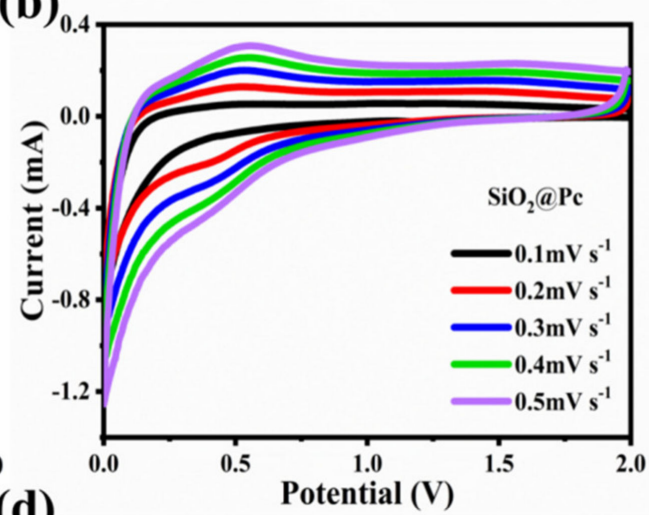

(d)

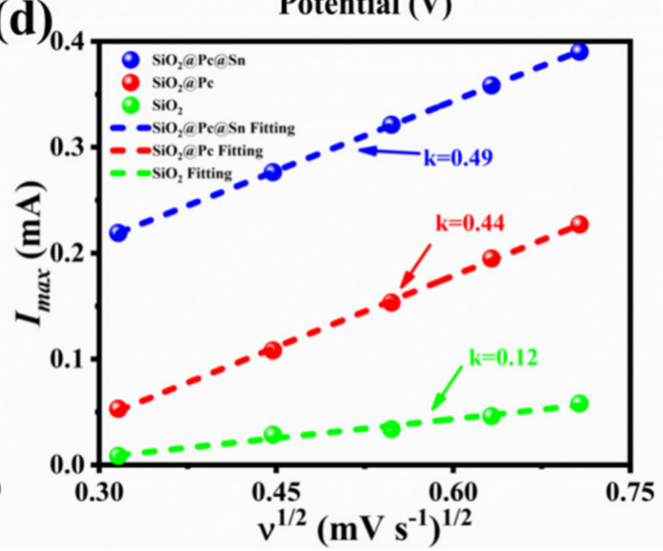

Figure 6. (a-c) CV curve of $\mathrm{SiO}_{2}, \mathrm{SiO}_{2} @ \mathrm{Pc}$, and $\mathrm{SiO}_{2} @ \mathrm{Pc} @ S n$ with different scanning rates of $0.1-0.5 \mathrm{mV} \cdot \mathrm{s}^{-1}$; (d) relationship between scan rate and peak current. 


\section{Summary}

The $\mathrm{SiO}_{2} @ \mathrm{Pc} @ S n$ composite anode material was prepared by the freeze-drying and low-temperature thermal melting method, which exhibited improved electrochemical performance and faster $\mathrm{Li}^{+}$transfer kinetic. The synergetic effect of porous carbon, $\mathrm{SiO}_{2}$, and $\mathrm{Sn}$ endows the as-fabricated $\mathrm{SiO}_{2} @ \mathrm{Pc} @ \mathrm{Sn}$ composites to be competent to show good electrochemical performance. When used as an anode in LIBs, the $\mathrm{SiO}_{2} @ \mathrm{Pc} @ S n$ composite could deliver a large reversible capacity of 650 at $100 \mathrm{~mA} \cdot \mathrm{g}^{-1}$, a remarkable rate capability of 500 retained at $1000 \mathrm{~mA} \cdot \mathrm{g}^{-1}$, and a long-term cycling durability with $\sim 87 \%$ capacity retention over 100 cycles. EIS and CV measurements demonstrated that, with the participation of Sn phase and Pc, the diffusion and migration kinetics of $\mathrm{Li}$ ions in $\mathrm{SiO}_{2} @ \mathrm{Pc} @ S n$ composites was significantly improved. The understanding of the synergistic effect of $\mathrm{Li}$ storage between $\mathrm{SiO}_{2}$ and $\mathrm{Sn}$ in this work will not only provide insight towards exploring new $\mathrm{SiO}_{2}$-based anode materials, but also shed light on the design of other low-cost and environmentally friendly electrode materials for the next-generation LIBs.

Author Contributions: Conceptualization, X.D.; methodology, X.D.; software, D.L.; validation, X.D., D.L. and H.Z.; formal analysis, X.D. and D.L.; investigation, X.D., D.L.; resources, X.D.; data curation, D.L., H.Z.; writing—original draft preparation, X.D.; writing—review and editing, X.D.; visualization, X.D., D.L. and H.Z.; supervision, X.D.; project administration, X.D.; funding acquisition, X.D. All authors have read and agreed to the published version of the manuscript.

Funding: This work was supported by the National Natural Science Foundation of China (No.11874282, 11604245, 11981240429), the Six Talent Peaks Project in Jiangsu Province (No. 2019-XNY-074), the Vice President Project of Industry-University-Research Cooperation in Science and Technology of Jiangsu Province (No. BY2020675).

Institutional Review Board Statement: Not applicable.

Informed Consent Statement: Not applicable.

Data Availability Statement: Data sharing not applicable.

Conflicts of Interest: The authors declare no conflict of interest.

\section{References}

1. Zhang, J.-N.; Li, Q.; Ouyang, C.; Yu, X.; Ge, M.; Huang, X.; Hu, E.; Ma, C.; Li, S.; Xiao, R.; et al. Trace doping of multiple elements enables stable battery cycling of LiCoO2 at 4.6 V. Nat. Energy 2019, 4, 594-603. [CrossRef]

2. Yang, C.; Ji, X.; Fan, X.; Gao, T.; Suo, L.; Wang, F.; Sun, W.; Chen, J.; Chen, L.; Han, F.; et al. Flexible Aqueous Li-Ion Battery with High Energy and Power Densities. Adv. Mater. 2017, 29. [CrossRef] [PubMed]

3. Yang, H.; Wu, H.-H.; Ge, M.; Li, L.; Yuan, Y.; Yao, Q.; Chen, J.; Xia, L.; Zheng, J.; Zhao, Y.; et al. Simultaneously Dual Modification of Ni-Rich Layered Oxide Cathode for High-Energy Lithium-Ion Batteries. Adv. Funct. Mater. 2019, 29, 1808-1825. [CrossRef]

4. Li, L.; Fang, C.; Wei, W.; Zhang, L.; Ye, Z.; He, G.; Huang, Y. Nano-ordered structure regulation in delithiated Si an-ode triggered by homogeneous and stable Li-ion diffusion at the interface. Nano Energy 2020, 72, 104651. [CrossRef]

5. Han, M.; Yu, J. Subnanoscopically and homogeneously dispersed SiOx/C composite spheres for high-performance lithium ion battery anodes. J. Power Sources 2019, 414, 435-443. [CrossRef]

6. Doughty, D.H.; Crafts, C.C. Freedom CAR Electrical Energy Storage System Abuse Test Manual for Electric and Hybrid Electric Vehicle Applications; Sandia Report SAND2005-3123; Sandia National Laboratories: Albuquerque, NM, USA; Livermore, CS, USA, 2006.

7. Commission NDAR, QC/T-743-2006. Automotive standard of the People's Republic of China: Lithium Ion Bateries for Electric Vehicles. 2006. Available online: https://max.book118.com/html/2017/0726/124432928.shtm (accessed on 13 February 2021).

8. Perner, A.; Vetter, J. Lithium-ion batteries for hybrid electric vehicles. In Advances in Battery Technologies for Electric Vehicles; Elsevier BV: Amsterdam, The Netherlands, 2015; pp. 173-190.

9. Cabana, J.; Monconduit, L.; Larcher, D.; Palacín, M.R. Beyond Intercalation-Based Li-Ion Batteries: The State of the Art and Challenges of Electrode Materials Reacting Through Conversion Reactions. Adv. Mater. 2010, 22, E170-E192. [CrossRef]

10. Whittingham, M.S. ChemInform Abstract: Ultimate Limits to Intercalation Reactions for Lithium Batteries. ChemInform 2015, 114, 11414-11443. [CrossRef]

11. Zhang, Q.; Uchaker, E.; Candelaria, S.L.; Cao, G. ChemInform Abstract: Nanomaterials for Energy Conversion and Storage. Cheminform 2013, 44. [CrossRef]

12. Masquelier, C.; Croguennec, L. Polyanionic (Phosphates, Silicates, Sulfates) Frameworks as Electrode Materials for Rechargeable Li (or Na) Batteries. Chem. Rev. 2013, 113, 6552-6591. [CrossRef] [PubMed] 
13. Song, H.-K.; Lee, K.T.; Kim, M.G.; Nazar, L.F.; Cho, J. Recent Progress in Nanostructured Cathode Materials for Lithium Secondary Batteries. Adv. Funct. Mater. 2010, 20, 3818-3834. [CrossRef]

14. Jia, H.; Gao, P.; Yang, J.; Wang, J.; Nuli, Y.; Yang, Z. Novel Three-Dimensional Mesoporous Silicon for High Power Lithium-Ion Battery Anode Material. Adv. Energy Mater. 2011, 1, 1036-1039. [CrossRef]

15. Ding, X.; Liu, X.; Huang, Y.; Zhang, X.; Zhao, Q.; Xiang, X.; Li, G.; He, P.; Wen, Z.; Li, J.; et al. Enhanced electrochemical performance promoted by monolayer graphene and void space in silicon composite anode materials. Nano Energy 2016, 27, 647-657. [CrossRef]

16. Tao, W.; Wang, P.; You, Y.; Park, K.; Wang, C.-Y.; Li, Y.-K.; Cao, F.-F.; Xin, S. Strategies for improving the storage per-formance of silicon-based anodes in lithium-ion batteries. Nano Res. 2019, 12, 1739-1749. [CrossRef]

17. Ding, X.; Wang, Y. Bilayer-graphene-coated Si nanoparticles as advanced anodes for high-rate lithium-ion bat-teries. Electrochim. Acta 2020, 329, 134975. [CrossRef]

18. Luo, J.; Tao, X.; Zhang, J.; Xia, Y.; Huang, H.; Zhang, L.; Gan, Y.; Liang, C.; Zhang, W. Sn4+ Ion Decorated Highly Conductive Ti3C2 MXene: Promising Lithium-Ion Anodes with Enhanced Volumetric Capacity and Cyclic Performance. ACS Nano 2016, 10, 2491-2499. [CrossRef]

19. Ding, X.; Wang, H.; Liu, X.; Gao, Z.; Huang, Y.; Lv, D.; He, P.; Huang, Y. Advanced anodes composed of graphene encapsulated nano-silicon in a carbon nanotube network. Rsc Adv. 2017, 7, 15694-15701. [CrossRef]

20. Li, W.; Feng, X.; Chen, Y. High performance lithium battery anode materials by coating $\mathrm{SiO}_{2}$ nanowire arrays with PEO. New J. Chem. 2019, 43, 14609-14615. [CrossRef]

21. Yi, X.; Yu, W.J.; Tsiamtsouri, M.A.; Zhang, F.; He, W.; Dai, Q.; Hu, S.; Tong, H.; Zheng, J.; Zhang, B. Highly conductive C-Si@G nanocomposite as a high-performance anode material for Li-ion batteries. Electrochim. Acta 2018, 295, 295. [CrossRef]

22. Liu, Y.; Jing, S.X.; Luo, S.H.; Li, S.H. Silicon oxides: A promising family of anode materials for lithium-ion batteries. Nat. Prod. Rep. 2019, 36, 626-665. [CrossRef] [PubMed]

23. Tang, C.; Liu, Y.; Xu, C.; Zhu, J.; Wei, X.; Zhou, L.; He, L.; Yang, W.; Mai, L. Ultrafine Nickel-Nanoparticle-Enabled SiO 2 Hierarchical Hollow Spheres for High-Performance Lithium Storage. Adv. Funct. Mater. 2018, 28, 1704561. [CrossRef]

24. Favors, Z.; Wang, W.; Bay, H.H.; George, A.; Ozkan, M.; Ozkan, C.S. Stable cycling of $\mathrm{SiO}_{2}$ nanotubes as high-performance anodes for lithium-ion batteries. Sci. Rep. 2014, 4, 4605.

25. Chang, W.-S.; Park, C.-M.; Kim, J.-H.; Kim, Y.-U.; Jeong, G.; Sohn, H.-J. Quartz $\left(\mathrm{SiO}_{2}\right)$ : A new energy storage anode mate-rial for Li-ion batteries. Energy Environ. Sci. 2012, 5, 6895. [CrossRef]

26. Meng, J.; Cao, Y.; Suo, Y.; Liu, Y.; Zhang, J.; Zheng, X. Facile Fabrication of 3D $\mathrm{SiO}_{2} @$ Graphene Aerogel Composites as Anode Material for Lithium Ion Batteries. Electrochim. Acta 2015, 176, 1001-1009. [CrossRef]

27. Ichikawa, S.; Suda, J.; Sato, T.; Suzuki, Y. Lattice dynamics and temperature dependence of the first-order Raman spectra for? $\mathrm{SiO}_{2}$ crystals. J. Raman Spectrosc. 2003, 34, 135-141. [CrossRef]

28. Brijesh, K.; Dhanush, P.C.; Vinayraj, S.; Nagaraja, H.S. Monoclinic Wolframite $\mathrm{ZnWO} 4 / \mathrm{SiO}_{2}$ nanocomposite as an anode material for lithium ion battery. Mater. Lett. 2020, 275, 128108.

29. Di, F.W.; Wang, N.; Li, L.X.; Geng, X.; Yang, H.M.; Zhou, W.M.; Sun, C.G.; An, B.G. Coral-like porous composite material of silicon and carbon synthesized by using diatomite as self-template and precursor with a good performance as an-ode of lithium-ions battery. J. Alloy. Compd. 2021, 854. [CrossRef]

30. Shen, D.; Huang, C.; Gan, L.; Liu, J.; Gong, Z.; Long, M. Rational Design of Si@SiO 2 /C Composites Using Sustainable Cellulose as a Carbon Resource for Anodes in Lithium-Ion Batteries. ACS Appl. Mater. Interfaces 2018, 10, 7946-7954. [CrossRef]

31. Dong, X.; Zheng, X.; Deng, Y.; Wang, L.; Ju, Z. SiO 2 /N-doped graphene aerogel composite anode for lithium-ion batteries. J. Mater. Sci. 2020, 55, 13023-13035. [CrossRef]

32. Yao, Y.; Zhang, J.; Xue, L.; Huang, T.; Yu, A. Carbon-coated $\mathrm{SiO}_{2}$ nanoparticles as anode material for lithium ion bat-teries. J. Power Sources 2011, 196, 10240-10243. [CrossRef]

33. Li, M.; Li, J.; Li, K.; Zhao, Y.; Zhang, Y.; Gosselink, D.; Chen, P. $\mathrm{SiO}_{2} / \mathrm{Cu} /$ polyacrylonitrile-C composite as anode mate-rial in lithium ion batteries. J. Power Sources 2013, 240, 659-666. [CrossRef]

34. Li, W.; Wang, F.; Ma, M.; Zhou, J.; Liu, Y.; Chen, Y. Preparation of $\mathrm{SiO}_{2}$ nanowire arrays as anode material with en-hanced lithium storage performance. RSC Adv. 2018, 8, 33652-33658. [CrossRef]

35. Liang, Y.; Cai, L.; Chen, L.; Lin, X.; Fu, R.; Zhang, M.Q.; Wu, D. Silica nanonetwork confined in nitrogen-doped ordered mesoporous carbon framework for high-performance lithium-ion battery anodes. Nanoscale 2015, 7, 3971-3975. [CrossRef]

36. Pang, H.; Zhang, W.; Yu, P.; Pan, N.; Hu, H.; Zheng, M.; Xiao, Y.; Liu, Y.; Liang, Y. Facile Synthesis of Core-Shell Structured $\mathrm{SiO}_{2} @$ Carbon Composite Nanorods for High-Performance Lithium-Ion Batteries. Nanomaterials 2020, 10, 513. [CrossRef] [PubMed]

37. Namsar, O.; Autthawong, T.; Laokawee, V.; Boonprachai, R.; Haruta, M.; Kurata, H.; Yu, A.; Chairuangsri, T.; Sarakonsri, T. Improved electrochemical performance of anode materials for high energy density lithium-ion batteries through $\left.\mathrm{Sn}(\mathrm{SnO})_{2}\right)$ $\mathrm{SiO}_{2}$ /graphene-based nanocomposites prepared by a facile and low-cost approach. Sustain. Energy Fuels 2020, 4, $4625-4636$. [CrossRef]

38. Tang, C.; Li, N.; Sheng, J.; Zhou, L.; He, L.; Zhu, J.; Li, F.; Liu, Y.; Mai, L. Facile Synthesis of Bi2S3@SiO 2 Core-Shell Microwires as High-Performance Anode Materials for Lithium-Ion Batteries. J. Electrochem. Soc. 2017, 164, 6110-6115. [CrossRef] 


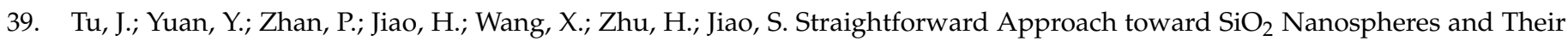
Superior Lithium Storage Performance. J. Phys. Chem. C 2014, 118, 7357-7362. [CrossRef]

40. Liu, D.D.; Kong, Z.; Liu, X.H.; Fu, A.P.; Wang, Y.Q.; Guo, Y.G.; Guo, P.Z.; Li, H.L.; Zhao, X.S. Spray-Drying induced assembly of skeleton-structured $\mathrm{SnO}_{2} /$ Graphene composite spheres as superior anode materials for high-performance lithium-ion batteries. ACS Appl. Mater. Inter. 2018, 10, 2515-2525. [CrossRef]

41. Xin, F.; Whittingham, M.S. Challenges and Development of Tin-Based Anode with High Volumetric Capacity for Li-Ion Batteries. Electrochem. Energy Rev. 2020, 3, 643-655. [CrossRef]

42. Wang, K.; He, X.; Ren, J.; Jiang, C.; Wan, C. Preparation of Sn/C microsphere composite anode for lithium-ion batteries via carbonthermal reduction. Electrochem. Solid St. 2006, 9, 320-323.

43. Derrien, G.; Hassoun, J.; Panero, S.; Scrosati, B. Nanostructured Sn-C Composite as an Advanced Anode Material in HighPerformance Lithium-Ion Batteries. Adv. Mater. 2007, 19, 2336-2340. [CrossRef]

44. Zhao, X.; Wang, W.; Hou, Z.; Yu, Y.; Di, Q.; Wu, X.; Wei, G.; Quan, Z.; Zhang, J. Monodisperse tin nanoparticles and hollow tin oxide nanospheres as anode materials for high performance lithium ion batteries. Inorg. Chem. Front. 2018, 6, 473-476. [CrossRef]

45. Tolosa, A.; Widmaier, M.; Krüner, B.; Griffin, J.M.; Presser, V. Continuous silicon oxycarbide fiber mats with tin nanoparticles as high capacity anode for lithium-ion batterie. Sustain. Energy Fuels 2018, 2, 215-228.

46. Huang, X.; Cui, S.; Chang, J.; Hallac, P.B.; Fell, C.R.; Luo, Y.; Metz, B.; Jiang, J.; Hurley, P.T.; Chen, J. A Hierarchical Tin/Carbon Composite as an Anode for Lithium-Ion Batteries with a Long Cycle Life. Angew. Chem. Int. Ed. 2014, 54, 1490-1493. [CrossRef] [PubMed]

47. Yan, Y.; Ben, L.; Zhan, Y.; Huang, X. Nano-Sn embedded in expanded graphite as anode for lithium ion batteries with improved low temperature electrochemical performance. Electrochim. Acta 2016, 187, 186-192. [CrossRef]

48. Zhao, Y.; Liu, Z.; Zhang, Y.; Mentbayeva, A.; Wang, X.; Maximov, M.Y.; Liu, B.; Bakenov, Z.; Yin, F. Facile Synthesis of SiO $@^{@ C}$ Nanoparticles Anchored on MWNT as High-Performance Anode Materials for Li-ion Batteries. Nanoscale Res. Lett. 2017, 12, 1-7. [CrossRef] [PubMed]

49. Wu, W.; Liang, Y.; Ma, H.; Peng, Y.; Yang, H. Insights into the conversion behavior of SiO-C hybrid with pre-treated graphite as anodes for Li-ion batteries. Electrochim. Acta 2016, 187, 473-479. [CrossRef]

50. Ma, B.; Luo, J.; Deng, X.; Wu, Z.; Luo, Z.; Wang, X.; Wang, Y. Hollow Silicon-Tin Nanospheres Encapsulated by N-Doped Carbon as Anode Materials for Lithium-Ion Batteries. ACS Appl. Nano Mater. 2018, 1, 6989-6999. [CrossRef]

51. Blanco, M.V.; Renman, V.; Vullum-Bruer, F.; Svensson, A.M. Nanostructured diatom earth $\mathrm{SiO}_{2}$ negative electrodes with superior electrochemical performance for lithium ion batteries. RSC Adv. 2020, 10, 33490-33498. [CrossRef]

52. Ma, B.; Lu, B.; Luo, J.; Deng, X.; Wu, Z.; Wang, X. The hollow mesoporous silicon nanobox dually encapsulated by $\mathrm{SnO}_{2} / \mathrm{C}$ as anode material of lithium ion battery. Electrochim. Acta 2018, 288, 61-70. [CrossRef]

53. Gu, Z.; Xia, X.; Liu, C.; Hu, X.; Chen, Y.; Wang, Z.; Liu, H. Yolk structure of porous $\mathrm{C} / \mathrm{SiO}_{2} / \mathrm{C}$ composites as. anode for lithium-ion batteries with quickly activated $\mathrm{SiO}_{2}$. J. Alloy. Compd. 2018, 757, 265-272. [CrossRef]

54. Chen, S.; Shen, L.; Aken, P.v.A.; Maier, J.; Yu, Y. Dual-Functionalized Double Carbon Shells Coated Silicon Nanoparticles for High Performance Lithium-Ion Batteries. Adv. Mater. 2017, 29. [CrossRef]

55. He, Y.; Xu, G.; Wang, C.; Xu, L.; Zhang, K. Horsetail-derived Si@N-doped carbon as low-cost and long cycle life anode for Li-ion half/full cells. Electrochim. Acta 2018, 264, 173-182. [CrossRef]

56. Park, C.-K.; Park, S.-B.; Oh, S.-H.; Jang, H.; Cho, W.-I. Li Ion Diffusivity and Improved Electrochemical Performances of the Carbon Coated LiFePO 4. Bull. Korean Chem. Soc. 2011, 32, 836-840. [CrossRef]

57. Wang, H.; Yang, X.; Wu, Q.; Zhang, Q.; Chen, H.; Jing, H.; Wang, J.; Mi, S.-B.; Rogach, A.L.; Niu, C. Encapsulating Silica/ Antimony into Porous Electrospun Carbon Nanofibers with Robust Structure Stability for High-Efficiency Lithium Storage. ACS Nano 2018, 12, 3406-3416. [CrossRef] [PubMed] 